\section{A Decade of JADPRO}

PAMELA HALLQUIST VIALE, RN, MS, CNS, ANP

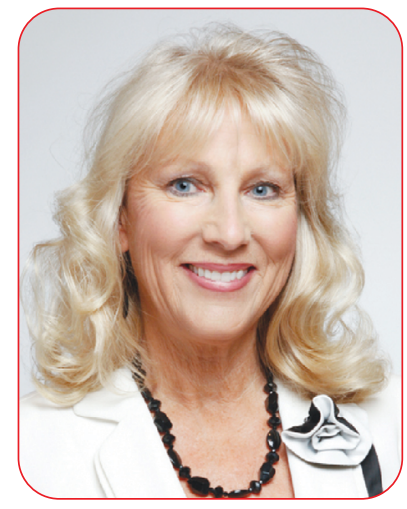

J Adv Pract Oncol 2020;11(5):451-452

https://doi.org/10.6004/jadpro.2020.11.5.1

(c) 2020 Harborside $^{\top M}$ s I write this editorial, JADPRO is celebrating a milestone. It was just over 10 years ago that the inaugural issue was published. Since that time, we've grown into a journal with a subscriber base of over 10,000, launched the Advanced Practitioner Society for Hematology and Oncology, APSHO (for which the journal is now the official publication), and developed an annual live meeting focused on the latest content to educate, support, and nurture the advanced practitioner. It's been quite a decade and I'm very proud of what we've accomplished.

\section{FIRST JOURNAL FOR APS}

Serving as your editor-in-chief has been the professional highlight of my career as an oncology/hematology NP. When Jack Gentile, Conor Lynch, and Anthony Cutrone, the principals of Harborside, first approached me back in 2009 to helm the first journal aimed at the advanced practitioner, I was honored to be asked and more than a little daunted by the task that lay before us. We had never had a specific journal targeted to our professions, and I was simply stunned that a publishing company was interested in creating a journal just for the advanced practitioner.

When we began our discussions on what the journal might be, Jack shared his vision for the publication and why he was focused on advanced practitioners. It was a personal mission for Jack. He'd completed an arduous journey of a new diagnosis of cancer coupled with challenging chemotherapy and radiation treatments. And although he had a stellar treatment team with many different members, the key professionals he turned to time and time again were advanced practitioners. As Jack was in the publishing business, he queried his advanced practitioners on what they depended on for education via the journals available. Jack was surprised that no one journal focused specifically on the advanced practitioner. $\mathrm{He}$ vowed to create something special for his cherished health-care professionals, and working with Conor and Anthony and a team of dedicated professionals at Harborside, the idea of JADPRO was born.

Being asked to serve as the inaugural editor-in-chief was an incredible professional gift. It was truly wonderful to gather accomplished advanced practitioner experts together to serve on the associate editor board. The board did a fantastic job of creating the features and columns that are in the publication that you now receive. The board worked diligently to shape the format for you, the reader of JADPRO. I am tru- 
ly grateful for how hard the associate editor board, reviewers, and the staff at Harborside work to create the journal we publish today. And I'm grateful to you, our loyal readers, for making JADPRO the journal you come back to again and again.

I would be remiss if I didn't mention the real reason we look so polished and professional as the premier journal and most relevant publication for advanced practitioners. Claudine Kiffer, our Editorial Director, Kelley Moore, our Acquisitions Editor, and Annie Yueh, our Editor, are devoted to making JADPRO the best journal of its kind published today. Without their tireless efforts, JADPRO would not be what it is today, and I am extremely grateful for their guidance and expertise.

\section{LOOKING AHEAD}

I find it amazing that a decade of JADPRO has swept by so quickly. But new challenges await me, and I am excited to turn over the editorial reins to Beth Faiman, PhD, MSN, APRN-BC, AOCN ${ }^{\circledR}$, FAAN, who will continue the excellence in publishing you've come to expect from JADPRO, creating new ideas and content to aid the advanced practitioner in the ever-changing landscape of oncology. It's been a wonderful and exciting decade, and I can't wait to see what new challenges JADPRO will meet in the future. Thank you for allowing me to serve as your Editor-in-Chief! It's truly been a fantastic experience and I know I leave you in good hands. 